\title{
Morpho-Histopathological Response of Phorate- An Organo-Phosphorous Pesticide on the Integumentary Musculature of an Epigeic Earthworm, Eisenia fetida
}

\author{
Suneel Kumar and S.M. Singh*
}
Earthworm Toxicology Unit, Earthworm Ecology and Environmental Research Laboratory, Department of Animal Science, Mahatma Jyotiba Phule Rohilkhand University, Bareilly-243006 (Uttar Pradesh), India
*Corresponding author

\begin{tabular}{|c|c|}
\hline & A B S T R A C T \\
\hline Keywords & \multirow{4}{*}{$\begin{array}{l}\text { Morphological and histo-pathological effects of a common broad spectrum systemic } \\
\text { organophosphate insecticide, Phorate (O, O-Diethyl S-(ethylthio) methyl phasphoroditl) } \\
\text { were evaluated on the integument of an epigeic earthworm, Eisenia fetida. The acute } \\
\text { toxicity experiments were conducted by direct contact test ( } 48 \mathrm{~h}) \text { through a filter paper } \\
\text { method recommended by OECD Guideline, } 207 \text {. The } \mathrm{LC}_{50} \text { value for } 48 \mathrm{~h} \text { was recorded } \\
\text { and it was } 20-40 \mu 1 \text {. Morphological alterations on the worm's skin and histological } \\
\text { observations showed coiling, curling and rupturing of body wall and formation of internal } \\
\text { glandular cell mass and disintegration of circular and longitudinal muscles, which failed to } \\
\text { regulate the internal coelomic pressure leading to fragmentation of body. The findings of } \\
\text { morphological and histo-pathological studies could be applied in the environmental risk } \\
\text { assessment of phorate. }\end{array}$} \\
\hline $\begin{array}{l}\text { Histology, Phorate, } \\
\text { OECD, Earthworm, } \\
\text { Eisenia fetida. }\end{array}$ & \\
\hline Article Info & \\
\hline $\begin{array}{l}\text { Accepted: } \\
\text { 15 March } 2017 \\
\text { Available Online: } \\
10 \text { April } 2017\end{array}$ & \\
\hline
\end{tabular}

\section{Introduction}

Synthetic pesticides are fairly well recognized as a cost-effective method of controlling pests, but these chemicals are toxic to other non-targeted and beneficial species. Pesticides are either directly applied to soil to control soil borne pests or deposited on soil as runoff from their foliar applications and these concentrations are highly enough to effect soil micro-organisms (Bezchlebova et al., 2007). Earthworms represent a major component of the soil biomass. The use of earthworms for testing toxicity is highly recommended by European communities (EC, 2004) and these are considered as testing animals for assessing the environmental health status of chemical pollution. Use of agricultural pesticides significantly affects the body wall of earthworms. In the present studies, an extensive work has been carried out to evaluate the morphological and histopathological changes on the body integument of an epigeic earthworm, Eisenia fetida due to use of phorate - a common organophosphate.

\section{Materials and Methods}

Phorate (O, O-Diethyl S-(ethylthio) methyl phasphoroditl) a common broad spectrum systemic organophosphate is used by the farmers to protect their crops from chewing, 
sucking and boring insects. It is very odious and highly poisonous pesticide. It not only creates adverse effects to soil organisms but lethal to them too. The acute toxicity experiments were conducted by direct contact test (48h) through a filter paper method recommended by OECD Guidelines, 207. The percent mortality of the worm, Eisenia fetida was recorded in different concentrations of phorate and the data were used to estimate the median lethal concentration $\left(\mathrm{LC}_{50}\right)$.

The histology of the body wall of control and experimental worms, Eisenia fetida was studied adopting the routine paraffin method (Humason, 1979). All the reagents used in the study were of analytical grade. Tissues of control and experimental earthworms were dissected and taken out, blotted free of mucus, washed thoroughly in physiological saline and cut in to pieces of desired size and fixed in bouins fluid fixative immediately after autopsy. Fixation was carried out at room temperature for $24 \mathrm{hr}$, after which the tissues were transferred to $70 \%$ alcohol. Several changes were made in $70 \%$ alcohol until the yellow color disappeared from the tissues. These tissues were dehydrated by passing through ascending grades of alcohol, cleaned in xylene, infiltrated with molten paraffin, and finally embedded in paraffin wax $\left(58^{0 \mathrm{C}} \mathrm{MP}\right)$. Sections of tissues of 5 micro meter thick were prepared and stained in hematoxylene and eosin, mounted in DPX and the slides were observed under the Olympus research microscope (CKX-41).

\section{Results and Discussion}

Morphological abnormalities like coiling, curling and rupture of body wall were observed in all the experimental worms. Excessive mucus secretion, less activeness, extrusion of coelomic fluid and body surface lesions were also noticed; although no any deformity was seen in the body wall of all the control worms. Significant epidermal, morphological deformities were observed in the $\mathrm{LC}_{50}$ exposed worms during the exposed tenure of $48 \mathrm{~h}$ (Fig.1B\&C). About $80 \%$ of exposed worms develop constrictions and swelling at the clitellar region (Fig.1D) and display multiple ruptures (Fig.1E). The worms developed breakages in the body wall with several lesions, which were leading to fragmentation of the body. Some worms developed breakages and shedding of cuticle which resembles ecdysis as like in insects and snakes (Fig.1 B).

Histo-pathological studies of the tissues of the body wall of earthworms kept under controlled condition showed normal architecture and intact nature of circular and longitudinal muscles (Fig. 2A); while of earthworms exposed to $\mathrm{LC}_{50}\left(20-40 \mu \mathrm{l} / \mathrm{cm}^{2}\right)$ for $48 \mathrm{~h}$ revealed the loss of architecture and showed a tendency to develop excess of glandular epithelium with the disintegration of cuticular membrane, ectodermal layer and expansion of spaces between the longitudinal muscles (Fig. 2B). The neighboring cells of circular and longitudinal muscles showed proliferation of glandular cells and erosion in ectodermal layer of the body wall (Fig. 2C) and discontinuation of cells (separated by narrow to large gap junctions). It may be due to necrosis depending up on the effect of toxicant (Fig. 2D). Damage in circular and longitudinal muscles and tissue erosion was prominent at $48 \mathrm{~h}$ toxicity of phorate which might lead to the fragmentation of the body (Fig. 2E). In addition, cloudy swellings were developed which were prominent in the longitudinal muscles after $48 \mathrm{~h}$ of exposure due to mild aberrations in cellular metabolism (Fig. 2F). 
Fig.1 Effect of phorate on Integumentary morphology of earthworm, Eisenia fetida during $48 \mathrm{~h}$ of phorate exposure
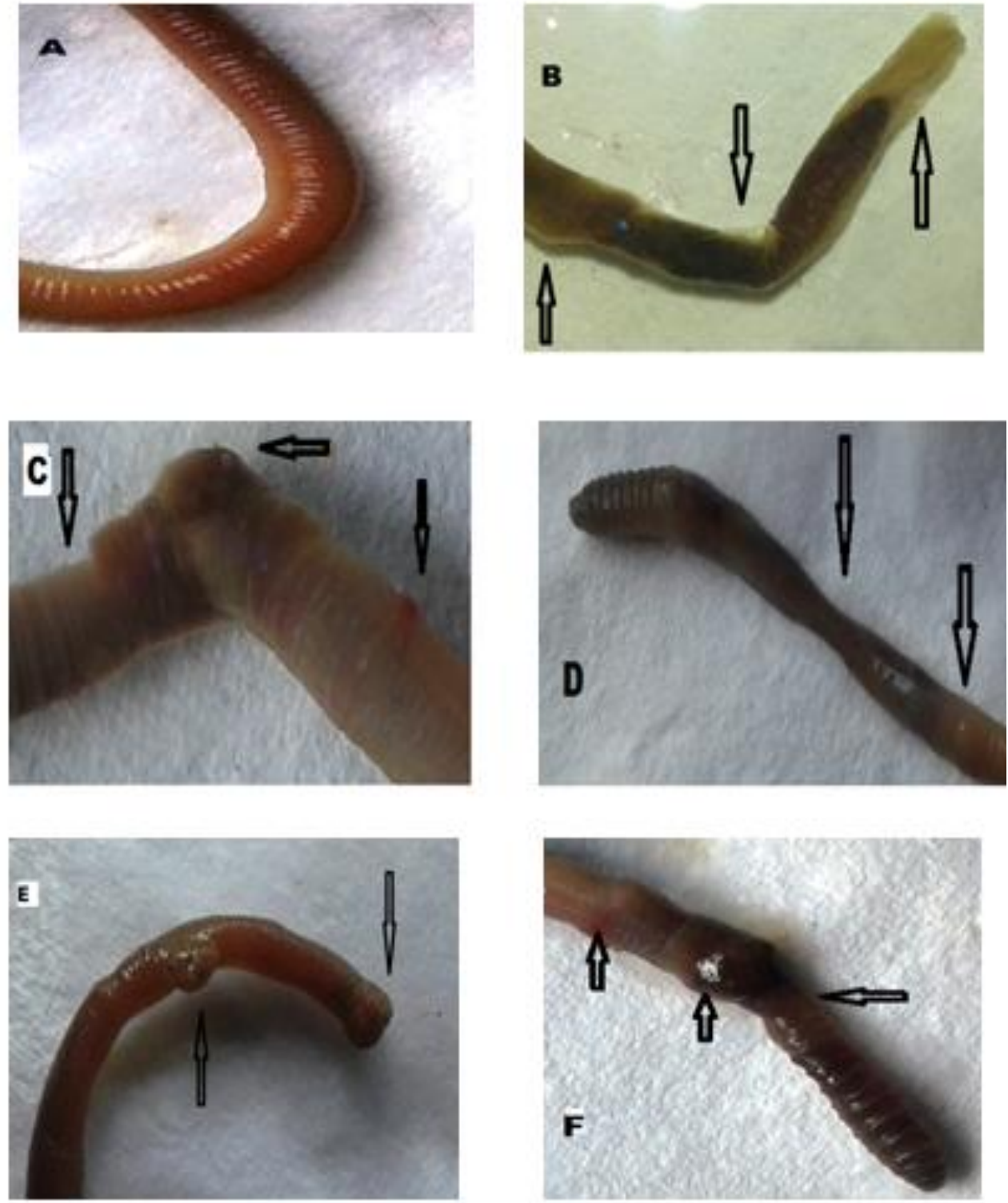

(A) Intact metameric segmentation in earthworm under controlled condition

(B) Multiple ruptures at body length and oozing of coelomic fluid

(C) Coiling of earthworm along with release of copious amount of mucous

(D) Breakage of body wall with partial disruption of metameric segmentation

(E) Self-protection mechanism in the anterior fragmented prostomial region and appearance of swelling

(F) Abnormal swelling at the clitellar region and mucus secretion 
Fig.2 Histo-pathological alterations in the muscle and body wall of earthworm, Eisenia fetida after $48 \mathrm{~h}$ exposure to phorate $\left(\mathrm{LC}_{50}\right)$ concentration using filter paper method
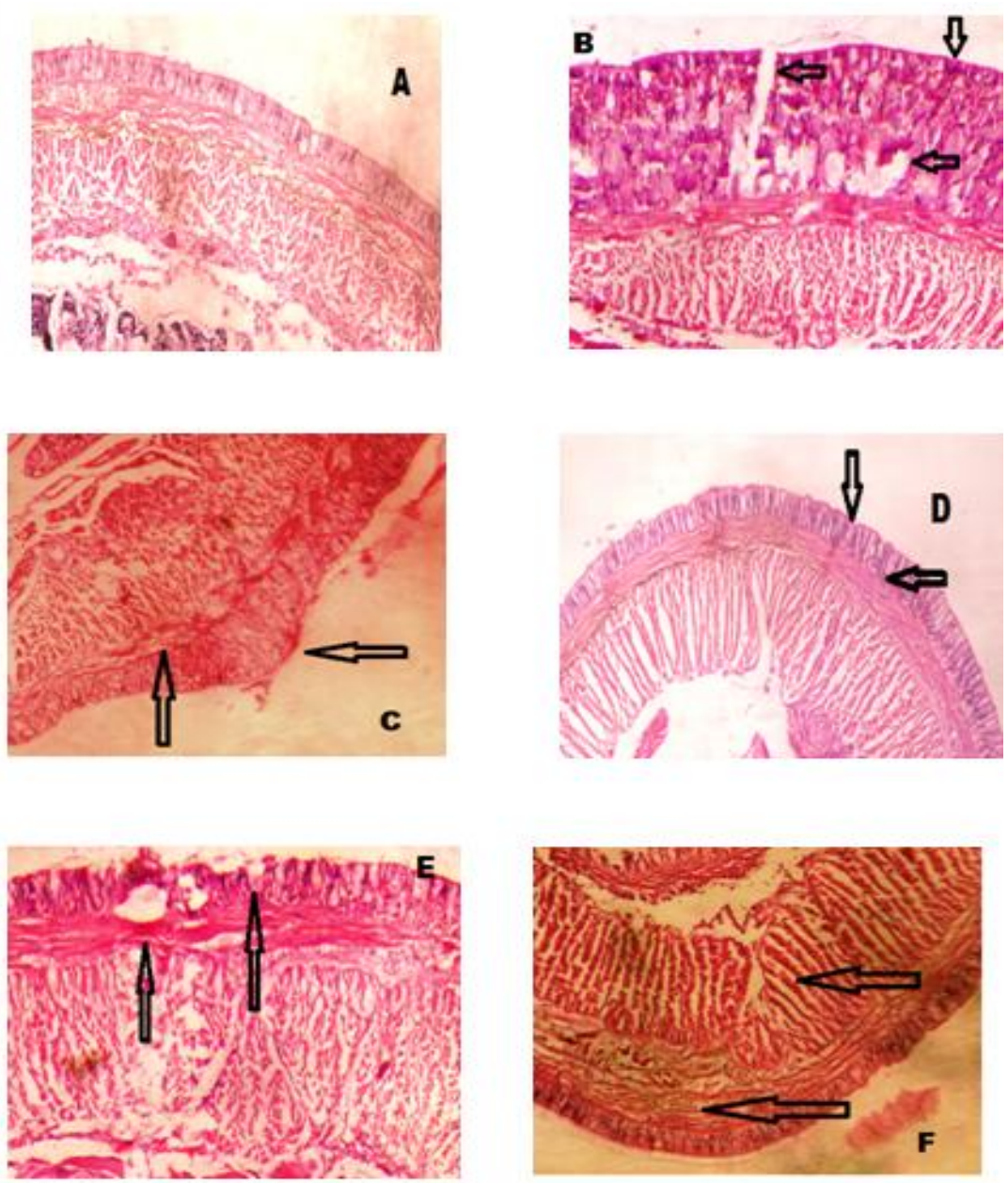

A).Intact Integumentary musculature in the earthworm under controlled condition

B).Enlargement of ectodermal cells and expansion of spaces between the longitudinal muscles

C). Proliferation of glandular cells and erosion of ectodermal layer

D) Necrosis of glandular cells and partial damage with cloudy swelling of longitudinal muscles

E) Damages in circular and longitudinal muscles and loss of structural integrity in longitudinal muscles

F) Erosion of internal and external tissues leading to total damage of body wall

Earthworms are one of the standard test organisms in evaluating the level of soil toxicity. These have broadly been used to assess environmental impact from heavy metal pollution. However, the knowledge of toxic effects of pesticides upon these organisms is still very limited. Earthworms are affected by pesticides either through skin contact or by feeding on contaminated litter in soil. Primarily, these toxicants passing through the skin reach the coelomic fluid and are thus transported throughout the body. Previous studies have suggested that earthworm's skin has direct contact to the 
contaminated soils and is considered as a significant route in the uptake of toxicants (Vijver et al., 2003). Epidermis and cuticle represent a primary barrier that protects earthworm's body from the environment and are also responsible for the transport of ions, thus allowing/blocking xenobiotics to enter the body (Clauss, 2001). The current investigations on the Eisenia fetida revealed that the contact toxicity of phorate through its integument was increased with increasing concentration and /or exposure time of the given toxicant. It is evident from the results that phorate can be rated as highly toxic to these earthworms with $\mathrm{LC}_{50}$ value 20-40 $\mu \mathrm{l} / \mathrm{cm}^{2}$ at $48 \mathrm{~h}$ of exposure. The present toxicant is comparatively several folds less toxic to Eisenia fetida in comparison to the earlier studies on other organophosphate (OP) insecticides (Venkateswara Rao et al., 2003b; Venkateswara Rao and Kavitha, 2004). However, work of Zang et al., (2000) revealed that these worms were highly sensitive to Chloronicotinoid insecticide, Imidacloprid with an $\mathrm{LC}_{50}$ of 0.1 and $0.034 \mu \mathrm{g}$ $\mathrm{cm}^{-2}$ after $24 \mathrm{~h}$ and $48 \mathrm{~h}$ of exposure, respectively.

The anatomical symptoms like coiling, abnormal swelling, fragmentation, rupture of body skin and loss of mucus etc., were noticed by the effect of phorate proved to be identical with the effects of lead acetate, tetra ethyl lead (TEL), methyl tetra-butyl ether (MTBE) (Venkateswara Rao et al.,2001, 2003a) and it was found quite similar in other species of earthworms, Perionyx excavates and Eisenia andrei after exposure to MTBE and Imidacloprid (Youn, 2005; Yvan et al., 2005).This happens when tissue in the body wall undergoes trauma or microscopic damage to an area by migration of toxicants or contaminations from the contact surface. During earthworm's exposure to phorate, epidermal cells underwent both hypertrophy and hyperplasia, increasing the thickness of the body wall. These progressive changes, such as hyperplasia and hypertrophy, can be considered as general defense mechanism against toxicants (Baynes and Hodgson, 2004), which increase the distance between external environmental and the internal organs and thus serve as a barrier for the entrance of xenobiotics (Poleksic et al., 2010). After $48 \mathrm{~h}$ exposure of phorate, a thinning of the earthworm's body wall started due to atrophy, which ultimately led to necrosis and erosion of the entire body wall. Despite this, without establishing link between changes in the epidermis and muscle layers, it is impossible to assess the level of the cell reaction. In the present findings the most of changes occurred in the clitellar and post clitellar regions (Fig. 2D, E, \& F). The histo-pathological evaluation revealed that the cuticular membrane and ectodermal layers were completely disintegrated and profusion of the glandular epithelium given a protection to the muscle layers of the body wall. It is evident from earlier reports that the morphological and histological changes were prominent when earthworms were exposed to different toxic metals and other OP pesticides (Amaral et al., 2006). Earthworms ingest large amounts of soil and are therefore elective non-target organisms exposed to pesticides through their external and internal surfaces. Present findings showed that phorate causes significant histo-pathological changes and acts as a destructive element to the experimental earthworm, Eisenia fetida. Thus morphological and anatomical changes in these organisms are one of the suitable indicators for monitoring the effectiveness of soil pollutants.

\section{Acknowledgement}

The senior author is grateful to the University Grants Commission, New Delhi, India for awarding PDF. 


\section{References}

Amaral, A., Soto, M., Cunha, R., Marigomez, I., Rodrigues, A. Bioavailability and cellular effects of metals on Lumbricus terrestris inhabiting volcanic soils. Environ. Pollut., 142(1): 103-108.

Baynes, R.E., Hodgson, E. 2004. Absorption and distribution of toxicants. In: Hodgson E. (ed.). A text book of modern toxicology, 3ed. Wiley \& son, New York, 77-110.

Bezchlebova, J., Cernohlavkova, j., Ivana Sochova, J., et al. 2007. Effects of toxaphene on soil organisms. Ecotoxicol. Environ. Saf., 6893: 326334.

Clauss, W. 2001. Epithelial transport and osmoregulation in annelids. Can. J. Zool., 79: 192-203.

E C. Biological test methods: tests for toxicity of contaminated soil to earthworms (Eisenia fetida, Eisenia andrei or Lumbricus terrestris).Report EPS 1/RM/43, Environment Canada, Environmental technology centre, 2004; Ottawa, ON, Canada.

Humason, G.L. 1979. Animal tissue techniques. $4^{\text {th }}$ ed. W.H. freeman \& co. San Francisco.

OECD-Organization for Economical Cooperation and Development Guideline for Testing of Chemicals. 1984. No.207, Earthworm Acute Toxicity, OECD. Paris, France.

Poleksic, V., Lenhardt, M., Jaric, I., et al. 2010. Liver, Gills and skin histopathology and heavy metals content of the Danube starlet (Acipenser ruthenus Linnaeus, 1758). Environ. Toxicol. Chem., 29(3): 515-521.

Venkateswara Rao, J., Kavita, P. 2004. Toxicity of azodrin on the morphology andacetyl cholinesterase activity of the earthworm (Eisenia fetida). Environ. Res., 96(3): 271-276.

Venkateswara Rao, J., Surya Pavan, Y., Madhavendra, S.S. 2003b. Toxic effects of chloropyrifos on survival, morphology and acetyl cholinesterase activity of the earthworm, Eisenia fetida. Ecotoxicol. Environ. Saf., 54: 296-301.

Vijver, M.G., Vink, J.P.M., Miermans, C.J.H., Gestel, C.A.M.V. 2003. Oral sealing using glue: a new method to distinguish between intestinal and dermal uptake of metals in earthworms. Soil Biol. Biochem., 35(1): 125-132.

Youn, J. 2005. Assessing soil ecotoxicity of methyl tert-butyl ether using earthworm bioassay; closed soil microcosm test for volatile organic compounds. Environ. Pollut., 134(2): 181-186.

Yvan, C., Rault, M., Costagliola, G., Mazzia, C. 2005. Lethal and sub lethal effects of Imidacloprid on two earthworm species (Aporrectodea nocturna and Allolobophora icterica).). Boil. Fertility Soil, 41(3): 135-143.

Zang, Y., Zhong, Y., Luo, Y., Kong, Z. M. Genotoxicity of two novel pesticides for the earthworm (Eisenia fetida). Environ. Poll., 108(2): 271-278.

\section{How to cite this article:}

Suneel Kumar and S.M. Singh. 2017. Morpho-Histopathological Response of Phorate - An Organo-Phosphorous Pesticide on the Integumentary Musculature of an Epigeic Earthworm, Eisenia fetida. Int.J.Curr.Microbiol.App.Sci. 6(4): 2048-2053. doi: https://doi.org/10.20546/ijcmas.2017.604.242 